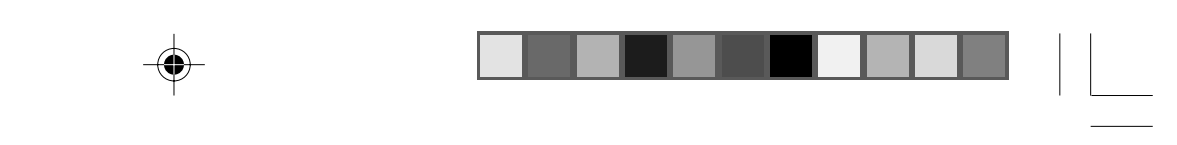

Imaginário - usp, 2007, vol. 13, n 14, 483-492

\title{
Eros invicto combatente
}

\author{
Ana Maria Portugal* \\ Fazer amor é poesia (LACAN. Sem. $X X)$.
}

No texto Kant com Sade (LACAN, 1962), em meio aos comentários sobre o grafo do fantasma sadiano, Lacan comenta a estática do fantasma, pela qual o ponto de afânise do sujeito deve ser infinitamente adiado, estática que Sade desenvolve em sua obra num plano de sistema, dotando as vítimas de suas fábulas de uma sobrevivência pouco crível. As vítimas, em sua multiplicidade de uma combinatória, exibem a monotonia da relação do sujeito submetido ao significante, ao passo que cabe aos atormentadores a função de objeto a do fantasma, por situar-se no real (LACAN, 1962, p. 786).

O sujeito, apesar de monótono, é belo. São belas as vítimas. A beleza é o último véu frente ao horror da Coisa. É lembrada Antígona (SÓFOCLES, s/d), no momento em que o coro estrondeia: - "Eros invicto combatente!"

Mas Antígona não cede, tendendo para a Lei da Coisa, essa Lei cuja injunção a faz consentir com seu destino: viva entre os mortos e morta entre os vivos. Sófocles invoca o Amor na palavra do Coro, logo após a sentença dada por Creonte. O canto do Coro louva Eros, o desejo, como o sedutor vitorioso que corre os oceanos e incendeia as paragens silvestres, atingindo mortais e imortais, responsável por essa guerra de consangüíneos.

*Psicanalista, membro da Escola Letra Freudiana - RJ. Doutora em Literatura Comparada pela FALE-UFMG. 


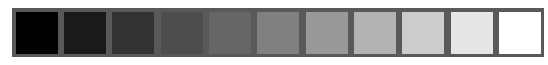

Portugal, A. M. Eros invicto combatente

Antígona é apathica (sem pathos) por excelência. E, como nada pode afetá-la, nada que a faça desistir de sua decisão trágica, ela não escuta o canto do Coro, nem os lamentos do Corifeu, pois já está além dessa lei pela qual o desejo vem nascer no mundo. Está além da lei do Amor. E condena-se a ser apenas sujeito petrificado, rochedo frio, de onde jorram lágrimas, última figura do hímeros agora caído e separado.

Podemos supor que, nessa passagem, o que Lacan quer apontar é que o apelo a Eros, invicto combatente não encontra ressonância na estática do fantasma. É preciso fazer entrar aí uma dinâmica. Foi o que Freud tentou com o mais além, com a nova dinâmica das pulsões, com a pulsão de morte (FREUD, 1969, p. 55-58). Porque Freud escuta a Eros. Serve a Eros para dele se servir (SALIBA, 1999, p. 36-38).

A primeira teoria freudiana das pulsões que coloca o conflito entre as pulsões do Eu e as pulsões sexuais - Eros, portanto - mostrase insuficiente na sustentação da clínica, pois, com as hipóteses sobre o narcisismo - amor ao Eu -, não se justifica mais tal conflito como causador das neuroses, já que Fome (pulsões do Eu) e Amor (pulsões sexuais) estão de um lado só (FREUD, 1920, p.72). No entanto, desde os artigos de 1910-1912, reunidos em "Contribuições para a psicologia do amor", a questão da depreciação do objeto sexual e a idealização do objeto amado (FREUD, 1970, p. 149-157), ao lado do caráter fundamentalmente parcial das pulsões, mostram uma depreciação geral do campo amoroso e uma tendência à insatisfação surgida na clínica como impotência psíquica.

Mais tarde, em 1915, associado aos artigos sobre a técnica, o amor vai de novo entrar em cena num destaque especial como um componente da transferência, componente ambíguo, cuja função é, ao mesmo tempo, motor e obstáculo ao prosseguimento do trabalho analítico. Referimo-nos ao artigo "Bemerkungen über Übertragungsliebe" (Observações sobre o amor de transferência) (FREUD, 1969, p. 207-222).

Trata-se aqui de um amor especial, desde que tem seu lugar na cena analítica - visto que é um amor de transferência - e cujo destino 
dependerá do manejo dela, o que corresponde, da parte do analista, menos a uma técnica que a uma posição.

Freud destaca que é uma situação única, agudamente circunscrita, tendo um significado real e sobre o qual o analista logo suspeita tratar-se de uma expressão de resistência, inibindo o tratamento e desviando o interesse do paciente pelo trabalho. Em suas palavras, refere-se a eine besondere Äusserung des Widerstandes (uma expressão especial da resistência), como podemos ver na seguinte passagem:

(...) mas tem-se antes de tudo a impressão de que a resistência incrementa die Verliebtheit (o estado amoroso) como agent provocateur ${ }^{1}$ e exagera a prontidão à entrega sexual, a fim de justificar ainda mais energicamente o efeito do recalcamento, alertando para os perigos de uma tal licenciosidade (FREUD, 1915, p. 212).

A resistência age, então, para mostrar que, na situação do amor, se atualiza algo que motivou o recalcamento e que insiste por meio da repetição. Freud pergunta-se como deve comportar-se o analista, desde que está convencido de que a travessia do tratamento deve prosseguir "apesar dessa Liebesübertragung (transferência de amor)" (FREUD, 1915, p. 213), que coloca a paciente pouco disposta ao trabalho, exigindo respostas à sua demanda de amor.

Notamos que aqui se inverteram os termos. O que antes seria descrito como Übertragungs-liebe (amor de transferência) passa agora a ser circunscrito como Liebes-übertragung (transferência de amor). Nessa inversão está a pequena diferença que faz situar o desejo do analista mais como uma posição que uma técnica. É preciso escutar para além da Liebesübertragung (transferência de amor). Se Freud dedicou ao tema do amor um item especial de sua maneira de trabalhar, o que se supõe é que o Übertragunsgsliebe (amor de transferência) é um instrumental a ser manejado no seu ponto de resistência, em que se escuta o dito de Sófocles: Eros invicto combatente!

Refere-se a uma resistência do dizer, em que algo da associação estanca, porque não há o que dizer². É por isso que nenhum discur${ }^{1}$ Em francês no original. Tra-
dução: agente provocador.

2 Freud escreve: “(...) as associações de um paciente versagen (faltam)" e acrescenta uma nota. "Quero dizer, quando elas realmente cessam, e não quando, por exemplo, o paciente as retém devido a sentimentos comuns de desprazer" (FREUD, 1969, p. 135). 


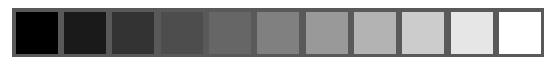

Portugal, A. M. Eros invicto combatente

so (padrões da moralidade, repressão pulsional, renúncia ou sublimação) tem sucesso nesse ponto. Como também não se trata de apelar para um comportamento intermediário, de retribuição parcial ao amor demandado, o que seria desconhecer o fundamento principal do tratamento em psicanálise: a Wahrhaftigkeit (o amor à verdade), que exclui qualquer tipo de impostura ou engano, na mesma medida em que o exigimos do paciente (FREUD, 1915, p. 214).

São três pontos importantes a manter em tensão frente aos anseios de satisfação amorosa: nicht verleugnen die Indifferenz (não desmentir a indiferença) com que são recebidos esses anseios; versagen (privar) sua satisfação; e conduzir o tratamento na Abstinenz (abstinência) não somente da satisfação direta, mas também de satisfações substitutas, pois concordar com elas seria o mesmo que recalcar (FREUD, 1915, p. 214).

Tais posições têm por objetivo manter a treibende Kraft (força pulsional) que leva ao trabalho e pressionar no sentido de efetuar mudanças. Se oferecermos ou aceitarmos qualquer substituto, o que presenciamos é apenas mais um fracasso dessa realização. (FREUD, 1915, p. 214). Tal amor deve ser mantido em suspenso, porque ele é de transferência. Sua presença se justifica, não para satisfação, mas para que algo seja desalojado nesse ponto fundamental em que é suposto um saber.

Isso dizemos porque, embora esse ensaio de Freud sobre o amor de transferência descreva especificamente situações de analistas homens com pacientes mulheres, o que aprendemos neste texto pode e deve ser pensado nas análises em geral. Tomando a

3 Em seu retorno a Freud, Lacan propõe a transferência como amor ao saber, especialmente em seu seminário sobre a transferência, na sessão de 10 março de 1961 (capítulo XII das edições oficiais) (LACAN, 1991). transferência como amor ao saber ${ }^{3}$, também o amor de transferência incidirá sobre esse mesmo ponto de resistência do discurso. É quando $o$ analisando confessa seu amor ao saber, exigindo que o saber responda, não tolerando a experiência do não-saber, a vigência da não-relação.

L'insu qui sait de l'une bevue s'aile a mourre. Este é o título proposto por Lacan em seu Seminário XXIV, que aconteceu em 1976-1977. $O$ insucesso do inconsciente é o amor - é o que podemos escutar 


\begin{abstract}
Imaginário - usp, 2007, vol. 13, n 14, 483-492
\end{abstract}
aí, no equívoco produzido pela homofonia na língua francesa. $\mathrm{O}$ amor é o ponto, no qual o inconsciente estruturado como uma linguagem fracassa. É, pois, um ponto importante de resistência, de algo que não se deixa vencer e onde o desejo do analista deve se posicionar. Nas palavras de Freud:

(...) o caminho do analista é outro, e tal que a vida real não fornece o modelo. Ele deve cuidar de não se desviar da Liebesübertragung (transferência de amor) ${ }^{4}$, de afugentá-la ou estragá-la para a paciente; e, ao mesmo tempo, recusar a retribuição. Manter a transferência de amor, tratá-la no entanto como algo Unreales (não real), como uma situação que, atravessando o tratamento, deve ser reconduzida às suas origens inconscientes (FREUD, 1915, p. 216).

O que é a origem inconsciente, a não ser o recalque primário, as fixações?

Em outro sentido, podemos dizer que é a origem inconsciente, a não ser o que acontece sob transferência na análise?

Esse é um ponto importante do artigo de Freud (1915, p. 218), por considerar como um fator mais decisivo para o analista o caráter genuíno do amor de transferência: é ter sido provocado pelo tratamento analítico. A intensificação desse amor pela resistência é um segundo fator, mas o fato é que a resistência não criou esse amor, já o encontrou e serviu-se dele exagerando suas manifestações. Se retomarmos a idéia de que a resistência é da ordem da resistência ao dizer que é no ponto da repetição que deve ser buscada a função da resistência. O terceiro fator - o desprezo do amor pela realidade, sua insensatez e cegueira em relação à avaliação da pessoa amada - postula as condições da transferência como suposição de saber. Vale de novo aqui a questão do amor ao saber.

Se lermos o artigo em seu todo, vemos que a preocupação de Freud é clarear para o analista os fundamentos da prática, propiciando linhas de trabalho que não o levem a ceder de sua dura posição de manter a tensão necessária para que o trabalho analítico possa acontecer.

\footnotetext{
4 Infelizmente, nessa passagem, a tradução da edição standard não mantém a diferença entre Liebesübertragung (transferência de amor) e Übertragungsliebe (amor de transferência), e traduz Liebesübertragung por amor transferencial, o que minimiza a importância dessa sutil inversão.
} 


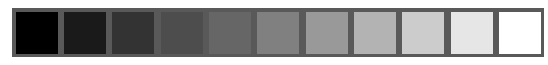

Portugal, A. M. Eros invicto combatente

\begin{abstract}
O psicanalista sabe que está trabalhando com forças as mais explosivas que, dele como dos químicos, exigem cuidados e escrúpulos. (...) Mas seria subestimar de forma grosseira as psiconeuroses em sua origem e significação prática, acreditar que estas afecções pudessem ser vencidas por meio de operações com remediozinhos inócuos (FREUD, 1915, p. 221).
\end{abstract}

5 (HEINE, s.d., p. 124).

Fragmentos do poema de Heine:

"Die Wanderratten (As ratas perambulantes)

Es gibt zwei Sorten Ratten:

die hungrigen und satten.

Die satten bleiben vernügt zu Haus die hungrigen aber wandern aus.

(Há dois tipos de ratas: / as famintas e as satisfeitas. As satisfeitas ficam em casa / as famintas perambulam).

" (...)

Heut helfen nicht die Wortgespinste der abgelebten Redekünste.

Man fängt nicht Ratten mit Syllogismen sie springen über die feinsten Sophismen."

(Hoje, de nada valem os enredamentos / das gastas artes verbais. / Não se prendem ratas com silogismos / elas saltam pelos mais finos sofismas).

"Im hungrigen Magen Eingang finden nur Suppenlogik mit Knödelgründen, nur Argumente von Rinderbraten, begleitet mit Göttinger Wurs-tzitaten."

(Em estômagos famintos só entra / a lógica da sopa com bolinhos por fundamentos, / carne assada por argumentos, / salsichas de Göttingen como acompanhamentos).
Essa valorização da neurose se deve a seu ponto de real, que permite às questões da satisfação e insatisfação outra leitura, coisa que fica implícita talvez no lapso de Freud, ao lembrar-se do poema de Heine, Die Wanderratten - As ratas perambulantes ${ }^{5}$. Freud diz: "[...] a lógica do sopa com bolinhos por argumentos." James Strachey, editor da Standard Edition, aponta-nos esse lapso, tendo Freud trocado a palavra fundamentos por argumentos. O verso de Heine diz: bolinhos por fundamentos. (FREUD, 1915, p. 216).

O poema de Heine é todo ironia e trata de ratas que perambulam porque estão famintas. Inicia-se assim: há dois tipos de ratas, as famintas e as saciadas. As saciadas se contentam em ficar em casa, e as insatisfeitas vão perambular. E por aí segue o poema, mostrando a resistência dessas ratas, que correm o mundo, céus, terras e mares, sem descanso, e ninguém pode contra elas, nem o Prefeito, nem o Senado, nem as armas etc. O que acontece é que ninguém prende ratas com discursos, silogismos e sofismas - diz o poema - pois, "(...) em estômagos famintos só entra a lógica da sopa, com bolinhos por fundamentos, carne assada por argumentos, salsichas como acompanhamentos."

Trocar fundamentos por argumentos pode bem passar por esse lapso, sem maiores considerações. Mas curioso é que, a partir dessa referência, que é concluída como um impasse para a psicanálise, ponto em que a satisfação é exigida de uma forma tão radical, Freud postula que o que resta é tentar entender porque a neurose se liga a tão obstinada necessidade de amor. É a lógica da neurose que se fundamenta e argumenta com seus bolinhos: a resistência e a repetição.

O significante argumentos surge daí em diante no texto, repetido algumas vezes. Os argumentos de Freud defendem a natureza 
desse amor como genuíno, exatamente pelos três fatores que apontamos acima: ele é provocado pelo tratamento, a resistência o exagera para servir-se dele e traz as condições de idealização, desprezo pela realidade e insensatez, como qualquer outro amor.

E poderíamos dizer mais, pois, se foi o analista que provocou a transferência de amor como amor ao saber, ele vai ter de dispor de algo a mais do que palavras para levar adiante seu ofício. Terá de dispor de um desejo de analista, aqui pensado como capaz de manter a tensão de não satisfação ao saber.

Lacan fala das aporias que o desejo do psicanalista demonstra no a posteriori do ato analítico (LACAN, 1995, p.26-43). Selecionamos três passagens de seu discurso à Escola Freudiana de Paris.

Assim, o desejo do psicanalista é esse lugar do qual estamos fora sem pensar nisso, mas onde, encontrar-se é ter saído dele realmente, ou seja, essa saída não tê-la tomado senão como entrada, e assim mesmo não qualquer uma, já que é a via do psicanalisante (LACAN, 1967, p. 30).

A que tem de responder o desejo do psicanalista? A uma necessidade que não podemos teorizar senão por dever fazer o desejo do sujeito como desejo do Outro, ou seja, fazer-se causa desse desejo (LACAN, 1967, p. 30).

(...) não se trata de modo algum de analisar o desejo do psicanalista. Não ousaremos nem mesmo falar de seu lugar exato, antes de ter articulado o que o necessita pela demanda do neurótico, a qual dá o ponto de onde ele não é articulável (LACAN, 1967, p. 37).

Esses fragmentos do discurso de Lacan à Escola Freudiana de Paris, retomados sobre a questão do amor de transferência, postulam a via que permanece aberta ao desejo do analista: um lugar onde não cabe o narcisismo, uma necessidade de colocar a função de causa do desejo e sua localização no ponto de resistência, do nãoarticulável. 


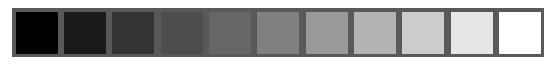

Portugal, A. M. Eros invicto combatente

Se o amor pode ser instrumento de transferência, na expressão freudiana amor de transferência, que seja como provocador e combatente.

Combatente invencível, mas nunca vencedor.

Resumo: O texto expõe sobre o amor de transferência como algo de dupla face: sendo motor importante em uma psicanálise, ao mesmo tempo é fonte de resistência ao tratamento. A transferência de amor ao saber, que a psicanálise sustenta na posição do analista, deve ser mantida como horizonte da análise e nunca confundida com o amor de transferência. Cabe ao analista acolher esse amor como genuíno, sem atendê-lo ou minimizá-lo, valendo-se, para tanto, do desejo do analista como um operador que mantém a tensão no ponto de não-saber.

Palavras-chave: psicanálise, amor de transferência, pulsões, desejo do analista (Lacan).

Abstract: The paper relates to the transference love as being double faced: it is, at the same time, a very important factor for the psychoanalysis development as well as a source of resistance to the psychoanalytical treatment. The transference of love to knowledge, which is sustained by the analyst's position during the treatment, must be maintained as the analysis horizon, and never be confused with transference love. The analyst should receive this love as a genuine one, although not responding to or underestimating it. For that, he/ she shall use the analyst's wish as an operator that maintains the tension at the point of suspension of knowledge.

Key words: psychoanalysis, transference love, drives, analyst's wish (Lacan). 
Resumen: El texto expone sobre el amor de transferencia como algo de doble cara: siendo motor importante en un psicoanálisis, al mismo tiempo que es fuente de resistencia al tratamiento. La transferencia de amor al saber, que el psicoanálisis sustenta en la posición del analista, debe ser mantenida como horizonte del análisis y nunca confundida con el amor de transferencia. Cabe al analista acoger este amor como genuino, sin corresponderle o minimizarlo, valiéndose, para tanto, del deseo del analista como un operador que mantiene la tensión en el punto de no-saber.

Palabras clave: psicoanálisis, amor de transferencia, pulsiones, deseo del analista (Lacan).

FREUD, S. Observações sobre o amor de transferência (1915 [1914]). In: Edição standard brasileira das obras completas de Sigmund Freud. Trad. Jayme Salomão. Rio de Janeiro: Imago, v. 12. p. 207222, 1969.

Além do princípio do prazer (1920). In: Edição standard brasileira das obras completas de Sigmund Freud. Tradução de Jayme Salomão. Rio de Janeiro: Imago, v. 18. p. 55-58, 1969.

. A dinâmica da transferência. (1912). In: Edição standard brasileira das obras completas de Sigmund Freud. Tradução de Jayme Salomão. Rio de Janeiro: Imago, v. 12, p.135, 1969.

Um tipo especial de escolha de objeto feita pelos homens

(1910). (Contribuições à psicologia do amor I). In: Edição standard brasileira das obras completas de Sigmund Freud. Trad. Jayme Salomão. Rio de Janeiro: Imago, v. 11. p.149-157, 1970.

L'insu qui sait de l'une bevue s'aile a mourre (1976-1977).

Paris, seminário inédito.

Le Séminaire. Livre VIII. Le Transfert (1960-1961). Paris:

Seuil, 1991. 


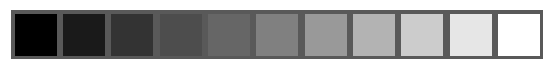

Portugal, A. M. Eros invicto combatente

. "Discurso à E.F.P." (1967). In: Letra Freudiana. Documentos para uma Escola II. Lacan e o Passe. Rio de Janeiro: Folha Carioca, p. 26-43. v. XIV, n. 0, 1995.

Kant com Sade (1962). In: Escritos. Tradução de Vera Ribeiro. Rio de Janeiro: Zahar, p.776-803, 1998.

HEINE, H. In: SANZ, W. (Org.) Aus dem Reichtum der Dichtung. 5te.Aufl. Wien: Österreichischer Bundesverlag, s.d., v.4, p. 124.

SALIBA, A. M. P. M. A substituição do amor em "Kant com Sade". In: Kant com Sade. Cadernos / Aleph-Psicanálise - Transmissão. Belo Horizonte: A4Design, v. 3, p.36-38, 1999.

SÓFOCLES. Antígona. Tradução de Fernando Melro. Lisboa: Editorial Inquérito, s.d.

e-mail: anamportugal@gmail.com

Recebido em 10/08/2006.

Aceito em 15/09/2006.

492 